\title{
Analysis of ergo-aesthetics assessment: a case study of public park benches
}

\begin{abstract}
Urban parks are recognized as an important feature that may improve the quality of urban life. Therefore, it is essential to design user preferable parks and accessories such as benches. Results show the lack of attention towards anthropometrics and user preference factors in designing have made these benches become unfavorable to the users and may even induce stress. This study aimed to redefine user preferences factors and the need for the ergoaesthetic design method model. As a conceptual framework, this research study included a review of previous research relevant to the scope of ñuser preferencesò in relation to various designs. A case study involving qualitative and quantitative method was used in this research in investigating reasons behind userôs preferences towards park benches. The case study was conducted among Putra Perdana Public Park, Putrajayaôs visitors. It is expected to serve as a reference point for future parks and their accessories design development in Malaysia. The research findings proved the lack of ergo-aesthetic factors on park benches and the need for an ergo-aesthetic design method model.
\end{abstract}

Keyword: Ergo-aesthetics; Benches; Public parks 